\title{
O uso do scratch no curso de pedagogia: relato de uma experiência interdisciplinar
}

\section{Rhêmora Ferreira da Silva Urzêda ${ }^{1}$, Eusiléa Pimenta Roquete Severiano ${ }^{2}$, Louis dos Santos Amorim ${ }^{3}$}

${ }^{1}$ Departamento de Sistemas de Informação do Centro Universitário do Planalto Central Apparecido dos Santos - (UNICEPLAC)

SIGA Área Especial para Industria $n^{\circ}$ 02, Setor Leste - CEP: 72.445-020 - Gama - DF Brasil

${ }^{2}$ Departamento de Pedagogia do Centro Universitário do Planalto Central Apparecido dos Santos- (UNICEPLAC)

SIGA Área Especial para Industria $n^{\circ}$ 02, Setor Leste - CEP: 72.445-020 - Gama - DF Brasil

${ }^{3}$ Departamento de Sistemas de Informação do Centro Universitário do Planalto Central Apparecido dos Santos - (UNICEPLAC)

SIGA Área Especial para Industria $n^{0}$ 02, Setor Leste - CEP: 72.445-020 - Gama - DF Brasil

rhemora@urzeda.com.br, eusilea@yahoo.com.br, louis_amorim@hotmail.com

Abstract. This article describes the experience of training students in the UNICEPLAC pedagogy course in the use of the Scratch tool, through an interdisciplinary extension project, with the participation of students in technological courses. The project intends to provoke the interaction and exchange of knowledge among students of courses with different curricula, in addition to presenting new technological skills to pedagogy students, so that in the future they may replicate in didactic practices carried out in the classroom. The active methodology applied was through "PBL" - Problem based learning, associated with the practices of "pair programming". Results indicate that the proposal adds computational knowledge to pedagogical practices.

Resumo. Este artigo descreve a experiência de capacitação de discentes do curso de pedagogia do UNICEPLAC no uso da ferramenta Scratch, por meio de projeto de extensão interdisciplinar, com participação dos discentes de cursos tecnológicos. O projeto pretende provocar a interação e troca de saberes entre os discentes de cursos com currículos diferenciados, além de apresentar novas competências tecnológicas às cursistas de pedagogia, para que futuramente repliquem nas práticas didáticas realizadas em sala de aula. A metodologia ativa aplicada se deu por meio de "PBL"- Problem based learning, associada às práticas de "pair programming". Resultados indicam que a proposta agrega conhecimento computacional às práticas pedagógicas. 


\section{Introdução}

Modernamente podemos observar cada vez mais a necessidade de utilizar recursos tecnológicos como facilitadores do processo de ensino aprendizagem. A tecnologia se mostra como facilitadora dos processos pedagógicos por trazer um sentido prático ao aprendizado teórico. Demonstrar na prática o que se aprendeu na teoria, por meio de recursos tecnológicos (programação), tem potencial transformador na medida em que estimula o desenvolvimento de novas habilidades aos estudantes de pedagogia.

No momento em que se formalizou o projeto de extensão por meio da parceria entre os cursos de pedagogia e sistemas de informação, o grande dilema se instalou na construção de adequada metodologia para desenvolver habilidades ligadas à programação junto aos discentes de ciências humanas. Muitas vezes, o futuro professor pretende incorporar a tecnologia nas rotinas pedagógicas, mas esbarra com limitações de ordem interna (falta de capacitação), e de ordem externa (falta de acesso aos computadores no ambiente escolar). Assim, não basta que o futuro professor tenha consciência da importância das novas tecnologias, se mostra como fundamental "ter algum conhecimento tecnológico, sem o qual será difícil uma tomada de decisão fundamentada e esclarecida." (COSTA et.al., 2012)

\section{O projeto de extensão NUTEC, aprendizagem compartilhada e uso da ferramenta Scratch.}

O desenvolvimento de atividades acadêmicas compartilhadas com os diversos cursos superiores pode auxiliar no processo de ensino aprendizagem, na medida em que colabora na troca de experiências de cada área do conhecimento. Nas palavras de Augusto et.al. (2004) "a interdisciplinaridade é entendida como a necessidade de integrar, articular, trabalhar em conjunto." A partir do projeto de extensão denominado NUTEC (Núcleo de Transformação Tecnologia e Capacitação), iniciou-se a interlocução dos cursos de tecnologia com outros cursos superiores do UNICEPLAC. Por uma demanda do curso de pedagogia o núcleo desenvolveu uma metodologia baseada na ferramenta Scratch, aplicada na capacitação dos discentes no que tange o desenvolvimento de novas competências relacionadas ao uso de tecnologias aplicadas ao ensino. A escolha da referida ferramenta se deu levando em consideração que muitos participantes do curso não possuíam intimidade com a tecnologia, sendo uma plataforma de simples utilização causando menos impacto aos discentes.

De acordo com Andrade et.al. (2013) o Scratch "é uma ferramenta concebida no Media Laboratory do Massachusetts Institute of Technology (MIT), sendo a mais recente de uma longa linhagem de ferramentas que se iniciou com a criação da linguagem de programação [...]." Ainda na visão do autor, a ferramenta permite uma linguagem simples e intuitiva referenciada por uma metodologia de "clicar e arrastar" através de blocos e de diversificadas mídias, possibilitando a criação de histórias interativas, animações, jogos, músicas e o compartilhamento dessas criações na Internet. Rodriguez (2015) define o Scratch como "uma linguagem de programação disponível online, desenvolvida com o objetivo de possibilitar que iniciantes possam criar programas de computador sem aprender a sintaxe de uma linguagem de programação." O aprendizado se dá por meio da programação em blocos de forma divertida e lúdica, com o desenvolvimento de jogos digitais e animações interativas (RODRIGUEZ et.al., 2015). 
Neste sentido, está entre os objetivos do projeto o uso desta ferramenta tecnológica no processo de formação das futuras pedagogas, com a apropriação da linguagem de programação a serem replicadas aos estudantes do ensino fundamental (anos iniciais), quando do exercício da atividade docente. A apropriação do "pensamento computacional" poderá favorecer o aluno do ensino fundamental (anos iniciais), no desenvolvimento de habilidades cognitivas voltadas ao raciocínio lógico, e "apoiar a aprendizagem de conceitos de lógica de programação de uma forma mais lúdica e adequada a essa faixa etária" (RODRIGUEZ et.al.). Nas palavras de Augusto et.al. (2004), "a necessidade de conectar conhecimentos, relacionar, de contextualizar é intrínseca ao aprendizado humano. Hoje, com a influência cada vez maior da tecnologia e da informática nas salas de aula, a ideia de rede de conhecimento torna-se seminal".

\section{O processo de construção metodológica e desenvolvimento das atividades}

A metodologia aplicada se deu de forma interdisciplinar, inicialmente com a seleção do estagiário de sistemas de informação para ministrar os encontros; após se deu a seleção e capacitação dos monitores para apoio nas dúvidas ao uso ferramenta Scratch; em seguida passou-se ao planejamento dos encontros e reserva do laboratório de informática para desenvolvimento das atividades com a aproximadamente 30 (trinta) discentes do curso de pedagogia.

A seguir passamos a discorrer sobre o conteúdo desenvolvido no curso de capacitação: os três primeiros encontros foram desenvolvidos por meio da associação de teoria e pequenos desafios práticos, dentro do primeiro encontro foram discorridas informações relacionadas à teoria de criação de jogos, qual seja, origens do Scratch, funções de movimento e controle. No segundo encontro foram trabalhadas atividades relacionadas à teoria de programação orientada à objetos; inclusão de objetos; funções de aparência. $\mathrm{O}$ terceiro encontro retratou a importação de objetos externos; funções de som; teoria de sensores; sensores do Scratch. No quarto encontro iniciou-se a abordagem da metodologia ativa PBL associada às práticas de pair programming (programação em pares), onde o problema norteador foi o desenvolvimento por meio de um jogo realmente aplicável no processo de ensino. Neste encontro os discentes realizaram o planejamento e iniciaram a execução do projeto final. No quinto e último encontro concluíram-se as atividades relacionadas ao projeto final e foi realizada a avaliação do curso (aplicação de questionário). No que se refere ao projeto final houve a construção em pares (pair programming) de um jogo digital realmente aplicável ao processo de ensino básico a partir de temas livres, sendo este o problema base do PBL. Ressalta-se, que a programação em pares se mostra adequada na medida em que os pares podem observar com maior propriedade possíveis erros no processo de programação, muitas vezes não detectados individualmente. O princípio do pair programming é utilizado em empresas na área de tecnologia para reforçar "a colaboração entre pares e acentuar a colaboração em atividade de desenvolvimento de software." (GARTNER et.al., 2012). Assim, durante o processo de desenvolvimento dos jogos, os pares trabalharam com o auxílio de uma única máquina, a partir do conceito de "piloto e copiloto", onde aquele que não se encontra em posse do computador "copiloto" seria o responsável por ministrar os comandos a serem executados pelo "piloto". Este projeto contou com a troca de papéis entre as duplas a cada 10 minutos, controladas de forma dinâmica pelos monitores. 
Ainda como parte do processo de execução da atividade final, utilizou-se o PBL, "problem based learning"que em português que quer dizer: aprendizagem baseada em problemas. Esta é uma metodologia ativa de ensino que utiliza um problema para motivar os alunos a adquirirem o conhecimento no processo de solução com o auxílio de um tutor. Na execução deste método durante o processo de capacitação, o tutor explicou o problema aos discentes e, junto com os monitores acompanhou os pares, explicando novos conceitos sempre que o par esbarrava em alguma limitação ao qual não encontrava a solução com facilidade. Assim, ao final, os estudantes de pedagogia foram instigados a produzirem em duplas jogos com temáticas livres, como atividade de encerramento do curso. A figura abaixo demonstra uma tela do trabalho final apresentada por uma dupla de discentes utilizando a metodologia Scratch.

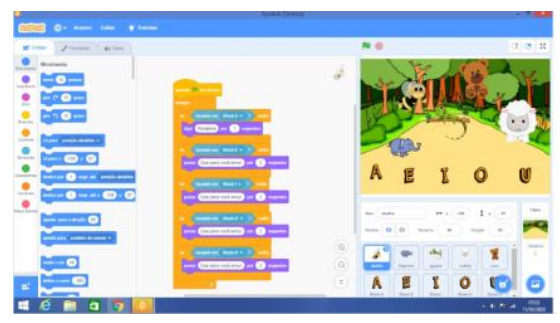

Figura 1. Retrato de tela do jogo com exemplo de alguns blocos de comandos.

\section{Resultados e discussões}

Conforme retratado anteriormente, a capacitação foi dividida em dois momentos, sendo três encontros teóricos e dois encontros práticos, iniciando com 31 participantes e finalizando com um número total de 16 participantes. De acordo com o gráfico abaixo, baseado no controle de frequência, é possível observar uma evasão crescente nos primeiros três encontros do curso, ou seja, nos encontros essencialmente teóricos. Entretanto, após o quarto encontro, cuja abordagem foi completamente prática, e associada ao PBL e Pair Programming, não se percebe grande evasão.

Gráfico 1. Presença dos alunos no curso

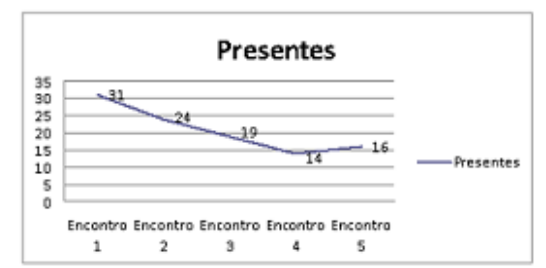

Fonte: elaboração própria a partir dos controles de frequências.

Apesar dos dados apresentados sugerirem um envolvimento maior dos discentes na segunda etapa da capacitação, deve-se ressaltar que uma abordagem um pouco mais teórica no início não poderia ser dispensada, levando em consideração o número significativo de discentes que não estavam familiarizados com o meio computacional. No mais, relatamos que ao final do último encontro, foi aplicado um questionário para avaliação da iniciativa e dos objetivos do curso. O referido instrumento foi aplicado de forma anônima e por meio digital, sendo que $87,5 \%$ dos participantes afirmaram que o curso atingiu seus objetivos; 93,8\% concordaram com a metodologia de ensino utilizada; $87,5 \%$ informaram que a abordagem prática foi suficiente; $87,5 \%$ disseram que a carga horária foi bem distribuída; 93,8\% apontaram que as instalações e recursos 
foram adequados; $100 \%$ dos alunos afirmaram que os conhecimentos adquiridos no curso poderão ser empregados em sua prática profissional; $81,3 \%$ classificaram seu aproveitamento em ótimo e 18,8\% classificaram como bom. Todos os alunos que avaliaram o curso participaram de no mínimo 4 encontros, o que sugere uma percepção real e positiva da capacitação como um todo. Como resultado do ponto de vista pedagógico observamos que o uso da ferramenta Scratch estimulou o aprendizado por meio do raciocínio lógico "com resolução de problemas de forma lúdica e dinâmica, além do desenvolvimento de noções básicas de programação." (RODRIGUEZ et.al., 2015)

\section{Considerações finais}

Apesar dos resultados positivos é importante ressaltar que durante o processo de capacitação encontramos algumas limitações, principalmente quanto à disponibilidade de horário para realização do curso, que por sua vez foi ministrado aos sábados, o que pôde ser considerado como possível causa de evasão. De forma geral, os objetivos foram alcançados, e a iniciativa do projeto demonstrou aos discentes dos diversos cursos da instituição, a necessidade de envolvimento deles em projetos que possam agregar novos saberes importantes ao contexto profissional.

\section{Referências}

AUGUSTO, Thaís Gimenez da Silva; CALDEIRA, Ana Maria de Andrade; CALUZI, João José. (2004). Interdisciplinaridade: concepções de professores da área ciências na natureza em formação em serviço. Ciência \& Educação, v. 10, n. 2, p. 277-289. Disponível em www.scielo.br/pdf/ciedu/v10n2/09.pdf. Acesso em: 08.03.2020.

COSTA, Fernando Albuquerque (Coord.); RODRIGUEZ, Carla; CRUZ, Elisabete; FRADÃO, Sandra. (2012). Repensar as TIC na educação: o professor como agente transformador. 1 ed. Lisboa: Santillana. Disponível em: www.researchgate.net/publication/299455917_Repensar_as TIC na_Educacao_O_P rofessor_como_Agente_Transformador. Acesso em: 06.03.2020.

GARTNER, Vilson C.; PINTO, Sergio Crespo C S Pinto; GÓMEZ, Arthur Torgo. (2012). Facilitando o aprendizado de programação sob a ótica de metodologias ágeis. RBIE V.20 N.1. Disponível em: pdfs.semanticscholar.org/7243/8af8cac9fb85653eac4077395de942f71e6e.pdf Acesso em: 08.03.2020.

RODRIGUEZ, Carla Lopes; LOPES, Aparecida M. Zem; MARQUES, Leonardo; ISOTANI, Seiji (2015). Pensamento Computacional: transformando ideias em jogos digitais usando o Scratch. Anais do XXI Workshop de Informática na Escola Universidade de São Paulo. São Carlos - SP. Disponível em: www.researchgate.net/publication/280302082_Pensamento_Computacional transfor mando_ideias_em_jogos_digitais_usando_o_Scratch . Acesso em: 08.03.2020.

ANDRADE Mariel; SILVA, Chérlia; OLIVEIRA, Thiago. (2013). Desenvolvendo games e aprendendo matemática utilizando o Scratch. XII SBGames - São Paulo $\mathrm{SP} \quad-\quad$ Brazil, October 16-18. Disponível em: www.sbgames.org/sbgames2013/proceedings/cultura/Culture-5_short.pdf. Acesso em: 29.06.2020. 